\title{
STRESS ANALYSIS IN RIGID ROADWAY PAVEMENT WITH DISCONTINUITIES SUBJECTED TO VEHICLE MOVEMENT
}

\author{
Sofia W. Alisjahbana*, Safrilah, Jouvan Chandra Putra Pratama, Ade Asmi \\ Civil Engineering Department, Faculty of Engineering and Informatics, Bakrie University, J1. \\ H.R. Rasuna Said Kav C-22, Jakarta 12410, Indonesia \\ Irene Alisjahbana \\ Ph.D. Student, Civil and Environmental Engineering Department, \\ Stanford University, Palo Alto, USA

\section{Buntara Sthenly Gan} \\ Department of Architecture, College of Engineering, \\ Nihon University, Koriyama, Japan \\ *Correspondence: sofia.alisjahbana@bakrie.ac.id
}

\begin{abstract}
Rigid concrete pavements subjected to several types of dynamic loading such as the vehicle movement loading that may result in joint cracking due to this type of loading. The objective of this study was to develop the modified Bolotin model of the rigid pavement to assess the vertical deflection, the flexural stress of the plate as well as the performance of dowel in rigid concrete pavement. The discontinuity between the plate is using dowels that restrain the rotation and the vertical deflection along the edges. The first and second type of Levy's problems is used to find eigenvectors of the pavement, while the eigenvalues are found from the transcendental equations in the $x$ and y-directions. Important factors that include the combined effects of loading velocity and the diameter of dowel are frequently ignored in most of the recent works. To overcome the inadequacies of the recent works, the present study investigated the rigid roadway pavement stress distribution under the effect of some model parameters. The results of the present study were verified by comparing with the other methods results from the recent study. Results showed that the stress distribution along the edges depends on the diameter of the dowel, the thickness of the rigid roadway pavement, and the soil conditions beneath it. In conclusion, to identify the effects of different features which include the geometry of the pavement, material properties the pavement and movement behavior of vehicles to the structural responses of rigid roadway pavement, the modified Bolotin method developed in the present study is suitable.
\end{abstract}


Sofia W. Alisjahbana, Safrilah, Jouvan Chandra Putra Pratama, Ade Asmi, Irene Alisjahbana, Buntara Sthenly Gan

Keywords: Dowel, Modified Bolotin Method, Rigid pavement, Stress distribution Vehicle movement.

Cite this Article: Sofia W. Alisjahbana, Safrilah, Jouvan Chandra Putra Pratama, Ade Asmi, Irene Alisjahbana, Buntara Sthenly Gan, Stress Analysis in Rigid Roadway Pavement with Discontinuities Subjected to Vehicle Movement. International Journal of Civil Engineering and Technology (IJCIET), 11(2), 2020, 174-182.

https://iaeme.com/Home/issue/IJCIET?Volume=11\&Issue=2

\section{INTRODUCTION}

In structural and transportation engineering applications, the dynamic response of orthotropic plates is an essential matter. Westergaard in the 1920s presented the first model of a rigid pavement as a slab sitting on the Winkler foundation [1]. In his study, the stresses and the deflections of the rigid pavement were calculated subjected to static loads located in the interior, the edge, and the corner of the plate [1]. Later in 1972, Wang et al. studied the response of the rigid pavement by including the load transfer devices which was not covered in the previous study done by Westergaard [2].

Analytical tool for modeling and analyzing the response of rigid pavements resting on elastic foundation had been conducted by the researchers for many years. The study of the effect of moving loads on the rigid pavement was done analytically and numerically by Fryba in 1972 [3]. Later in 2015, Lajcakova and Melcer studied numerically to simulate the moving load on the concrete pavements. In their study, it was shown that the responses of concrete pavement are influenced by the velocity of the vehicle and stiffness characteristics of the concrete pavements [4].

To model the strains and stresses distributions in a roller compacted concrete (RCC) pavements using the computer code Abaqus was done by Zdiri et al. in 2009. In their study, a numerical 3D modeling was used for analyzing the behavior law of the RCC, while 2D modeling was applied for the determination of the stress and strains in the RCC slab [5]. The results of their study showed that the computer code Abaqus is a reliable analysis tool to determine the deflections and stress in the RCC slab.

The study of the load transfer device in both directions of the transversal and longitudinal ways of the pavement, known as a dowel, was done by Byrum and Ye in 2012. Based on their study, the shorter slab length requires more substantial joints that raised the costs of construction [6]. In the advancement of the FEM, parametric studies on the jointed normal concrete pavement were done by Monireh et al. in 2017. The dowel bars as devices that are transferring the load through the joints were simulated by shearing and friction type of elements [5]. Their parametric study showed that the increasing slab thickness leads to the reduction of the strains and stresses in the concrete slabs.

Previous studies had shown some shortages by neglecting the proper element modeling of the dowel bars. In this study, the loading transfer devices through the joints which are expressed by using the edge vertical translation restriction and the edge rotational restriction coefficients. The combined effects of the moving load to the thickness of the rigid roadway pavement as well as the type of soil underneath the rigid roadway pavement to the maximum vertical deflection and the distribution of the stresses within the rigid roadway pavement region were determined in this study.

\section{MODEL OF THE RIGID ROADWAY PLATE}

The rigid concrete pavement sitting on elastics Pasternak foundation is modeled by using the Kirchhoff theory of thin plates that can be expressed by [7] 
Stress Analysis in Rigid Roadway Pavement with Discontinuities Subjected to Vehicle Movement

$D_{x} \frac{\partial^{4} W T}{\partial x^{4}}+2 B \frac{\partial^{4} W T}{\partial x^{2} \partial y^{2}}+D_{y} \frac{\partial^{4} W T}{\partial y^{4}}+\rho h \frac{\partial^{2} W T}{\partial t^{2}}+\xi h \frac{\partial W T}{\partial t}$

$-G_{s}\left(\frac{\partial^{2} W T}{\partial x^{2}}+\frac{\partial^{2} W T}{\partial y^{2}}\right)+k_{f} W T=f(x, y, t)$

where $D_{x}$ is the flexural rigidity of plate in the $x$-direction; $B$ is the torsional rigidity of plate, $D_{y}$ is the flexural rigidity of plate in the $y$-direction, $\rho$ is the mass density of plate, $h$ is the thickness of plate, $\xi$ is the damping ratio of plate, $G_{s}$ is shear modulus of Pasternak foundation, $k_{f}$ is the stiffness coefficient of Pasternak foundation and $f(x, y, t)$ is the vehicle load.

The vertical deflection of the plate $w(x, y, t)$ can be expressed as the multiplication of two functions

$$
w(x, y, t)=W T
$$

The function $W$ depends on coordinates $x, y$ in spatial field, and the function $T$ depends on time $t$ as the temporal field. According to Alisjahbana et al., the vertical deflection of the function $w(x, y, t)$ is the multiplication of the functions $W$ and $T$ that can be solved by means of the Modified Bolotin Method [8]:

$$
\begin{gathered}
W(x, y)=\left(A_{1} \cosh \frac{\beta \pi x}{a b}+A_{2} \sinh \frac{\beta \pi x}{a b}+A_{3} \sin \frac{p \pi x}{a}+A_{4} \cos \frac{p \pi x}{a}\right) \\
\left(B_{1} \cosh \frac{\theta \pi y}{a b}+B_{2} \sinh \frac{\theta \pi y}{a b}+B_{3} \sin \frac{q \pi y}{b}+B_{4} \cos \frac{q \pi y}{b}\right)
\end{gathered}
$$

and

$$
\begin{gathered}
T(t)=\frac{1}{\int_{0}^{a}(X(x))^{2} d x \int_{0}^{b}(Y(y))^{2} d y}\left(\frac{1}{\rho h \omega \sqrt{1-\xi^{2}}}\right) \int_{0}^{t}\left[\left[\int_{0}^{a} X(x) d x \int_{0}^{b} Y(y) d y\right] f(x, y, \tau)\right. \\
\left.\left(e^{-\xi \omega(t-\tau)}\right) \sin \left(\omega \sqrt{1-\xi^{2}}(t-\tau)\right)\right] d \tau
\end{gathered}
$$

where $A_{1}, \ldots, A_{4}$ are the constants of the spatial function in the $x$-direction, $B_{1}, \ldots, B_{4}$ are the constants of the spatial function in the $y$-direction, $\beta$ and $\theta$ are constants that can be found from the boundary conditions, $\omega$ is the circular frequency of the plate, and $p$ and $q$ are real numbers that can be found from the transcendental equations in the $x$ - and $y$-directions [9].
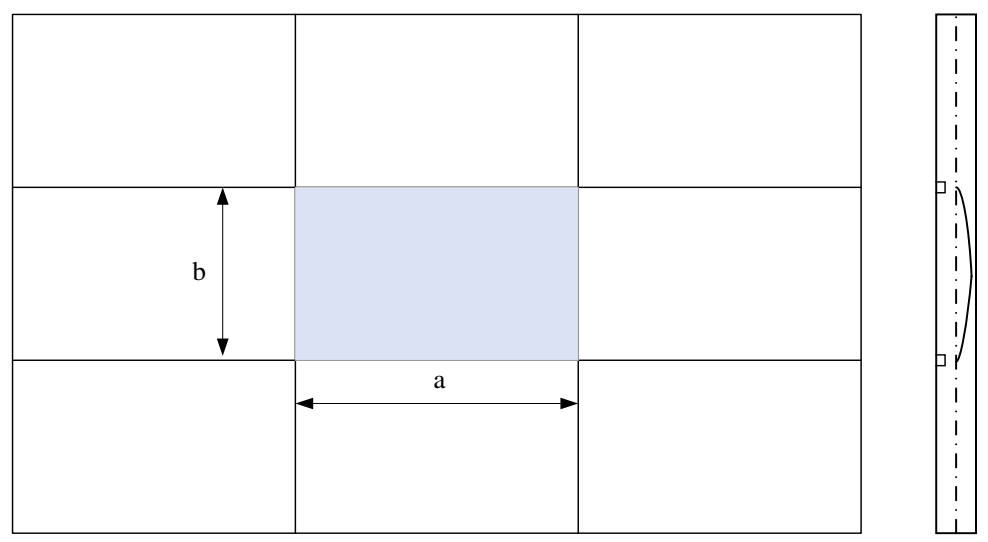

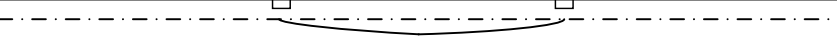

Figure 1. The deflection shape of plate model of the rigid pavement with discontinuities along the edges. 
The dynamic load $f(x, y, t)$ in equation (1) is the vehicle load which moving with constant velocity $v$ in the $x$-direction at the constant position $y=b / 2$ that can be given as

$$
\begin{aligned}
& f(x, y, t)=F_{0}\left(1+\alpha \cos \left(\omega_{v} t\right)\right) \delta[x-x(t)] \delta[y-y(t)] \\
& \quad=F_{0}\left(1+\frac{1}{2} \cos \left(\omega_{v} t\right)\right) \delta[x-v t] \delta\left[y-\frac{b}{2}\right]
\end{aligned}
$$

where $F_{0}$ is the weight of the vehicle, $\alpha$ is the coefficient of the vehicle type (for medium truck $\alpha=0.5), \omega_{v}$ is the circular frequency of vehicle, $\delta[$.$] is the Dirac delta function.$

Once the vertical deflection of the plate is determined by multiplying equations (3) and (4), then the state of stresses within the rigid pavement region can be computed by using the following formula:

$$
\begin{aligned}
\sigma_{x} & =\frac{E_{x}}{\left(1-v_{x} v_{y}\right)} \frac{h}{2}\left(\frac{\partial w(x, y, t)}{\partial x}+v_{y} \frac{\partial w(x, y, t)}{\partial y}\right) \\
\sigma_{y} & =\frac{E_{y}}{\left(1-v_{x} v_{y}\right)} \frac{h}{2}\left(\frac{\partial w(x, y, t)}{\partial y}+v_{x} \frac{\partial w(x, y, t)}{\partial x}\right) \\
\tau_{x y} & =\frac{\sqrt{E_{x} E_{y}}}{1+\sqrt{v_{x} v_{y}}} \frac{h}{2}\left(\frac{\partial}{\partial y}\left(\frac{\partial w(x, y, t)}{\partial x}\right)\right)
\end{aligned}
$$

\section{NUMERICAL ANALYSIS}

To conduct the numerical analysis, a rigid roadway pavement model sitting on two types of soil condition is considered, as shown in figure 2.
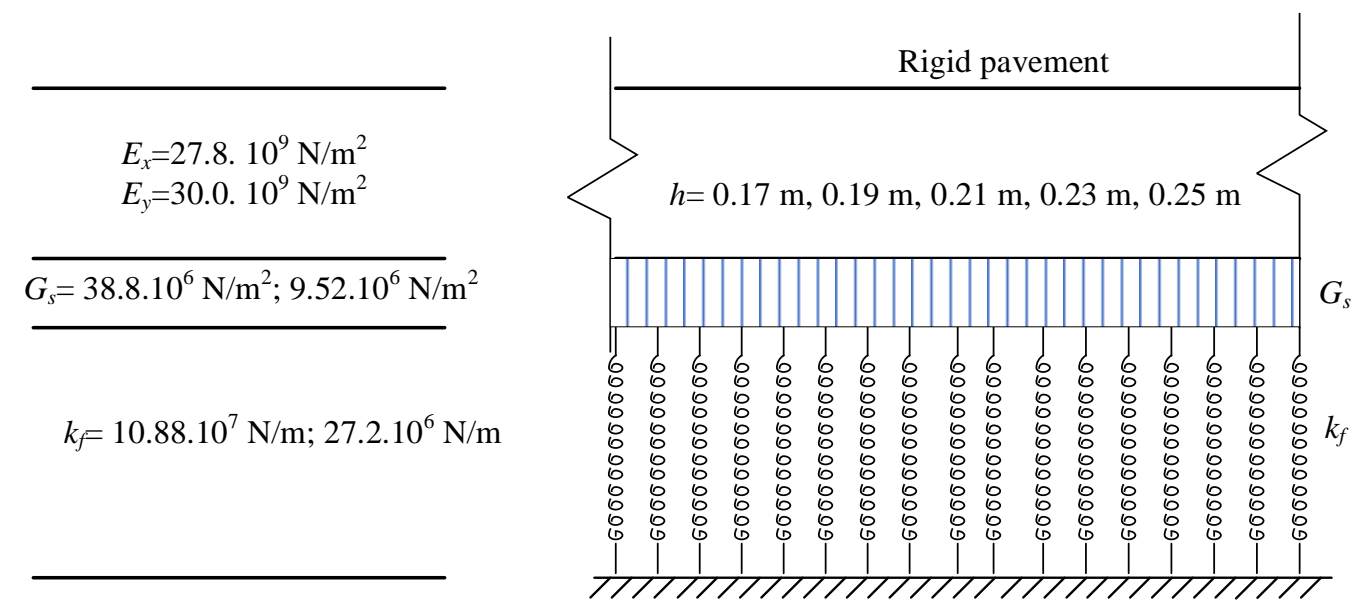

Figure 2. Model of the rigid roadway pavement on elastic Pasternak foundation.

The edge vertical translation restriction coefficients ( $k s x$ and $k s y)$ and the edge rotational restriction coefficients ( $k r x$ and $k r y)$ in the $x$ and $y$-direction are analyzed by using the method of Friberg [10], [8] and [11]. In this study, two sizes of dowel are used $22 \mathrm{~mm}$ and $28 \mathrm{~mm}$ dowel to determine the edge coefficients of vertical translation and rotational along the plate discontinuities. 
Stress Analysis in Rigid Roadway Pavement with Discontinuities Subjected to Vehicle Movement

Table 1. The edge vertical translation restriction and the edge rotational restriction coefficients

\begin{tabular}{|c|c|c|c|c|}
\hline Dowel diameter & $\boldsymbol{k} \boldsymbol{r} \boldsymbol{x}$ & $\boldsymbol{k r y}$ & $\boldsymbol{k s} \boldsymbol{x}$ & $\boldsymbol{k s y}$ \\
\hline$[\mathrm{mm}]$ & {$[\mathrm{Nm} / \mathrm{rad}]$} & {$[\mathrm{Nm} / \mathrm{rad}]$} & {$\left[\mathrm{N} / \mathrm{m}^{2}\right]$} & {$\left[\mathrm{N} / \mathrm{m}^{2}\right]$} \\
\hline 22 & $1.4479 .10^{7}$ & $2.2321 .10^{7}$ & $5.57385 .10^{7}$ & $5.57385 .10^{7}$ \\
\hline 28 & $1.4479 .10^{7}$ & $2.2321 .10^{7}$ & $8.68911 .10^{7}$ & $8.68911 .10^{7}$ \\
\hline
\end{tabular}

\subsection{Influence of the Vehicle Motion}

A computer program Mathematica 12.0 is used to calculate the rigid roadway pavement response numerically. The program enables to calculate time-dependent on the vertical deflection and the state of stresses of the system under the traffic load. The numerical results of the vertical deflections of the system for $v=60 \mathrm{~km} / \mathrm{h}$ and $\omega_{v}=100 \mathrm{rad} / \mathrm{s}$ are in figure 3 .

The effects of the velocity of the vehicle to the dynamic deflection of two soil conditions have been analyzed within an interval of speeds $v=5-150 \mathrm{~km} / \mathrm{h}$ by using $5 \mathrm{~km} / \mathrm{h}$ speed increment. The maximum dynamic deflection at the mid-span of the plate versus the velocity of the vehicle is drawn in figure 4. The results are obtained for the assumption that the condition of the road surface is smooth.

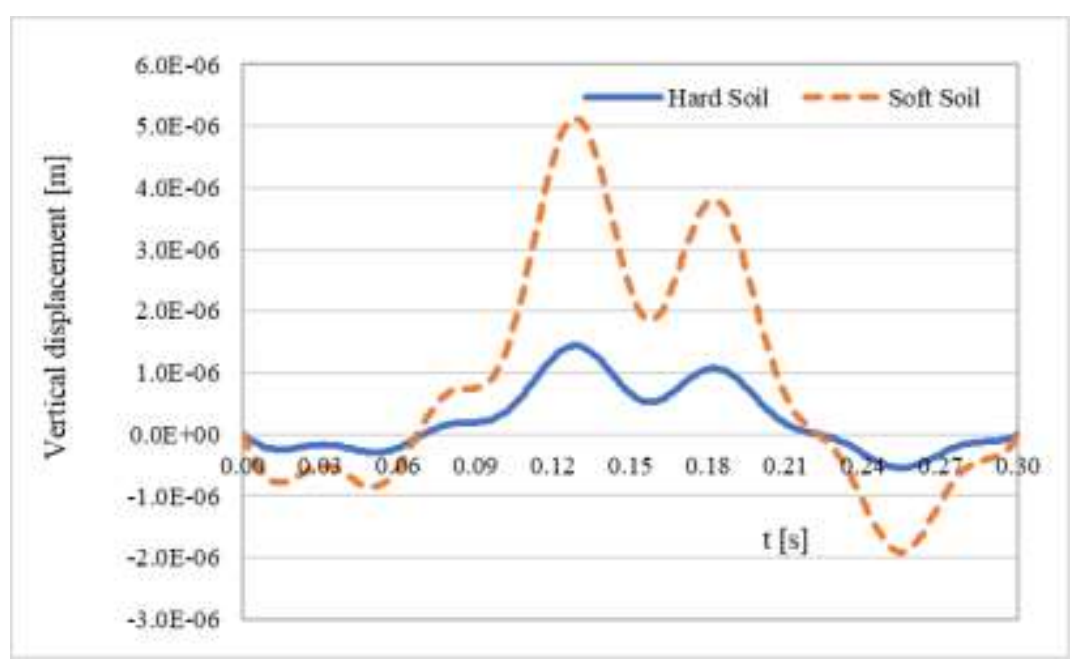

Figure 3. Vertical deflection at the mid-span of rigid pavement at the vehicle velocity $v=60 \mathrm{~km} / \mathrm{h}$.

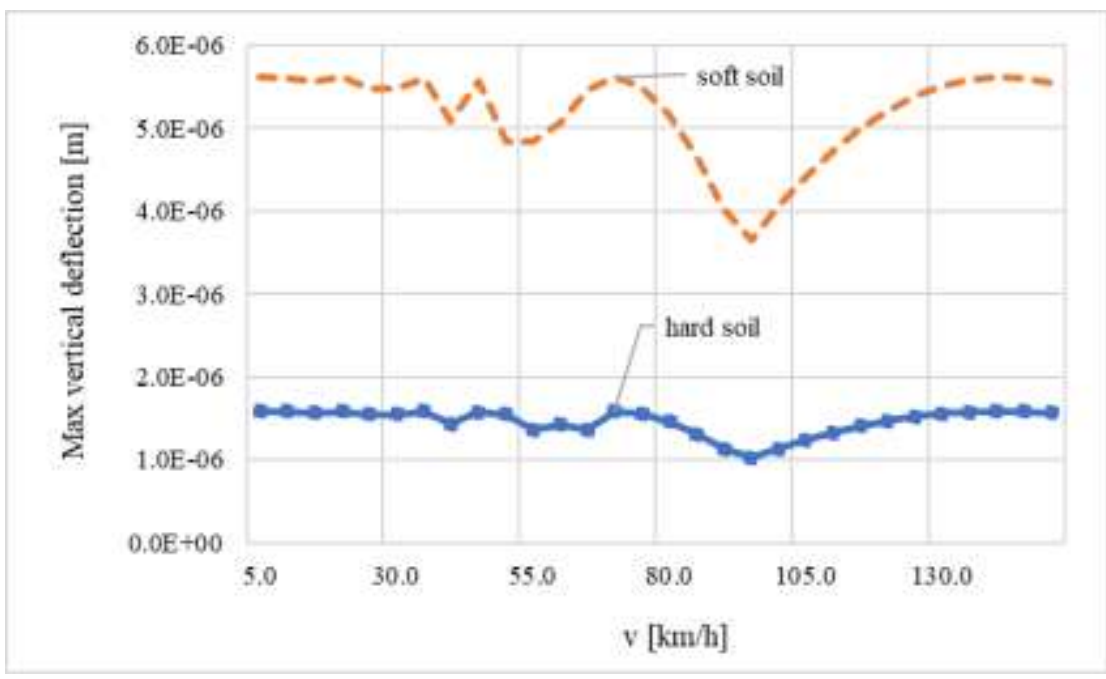

Figure 4. Maximum vertical deflection versus velocity $v$. 
The maximum vertical deflection of the rigid roadway pavement $w_{\max }=5.6101 .10^{-6} \mathrm{~m}$ for soft soil condition and $w_{\max }=1.58607 .10^{-6} \mathrm{~m}$ for hard soil condition. The correspond critical velocity of the vehicle $v=140 \mathrm{~km} / \mathrm{h}$ for both hard and soft soil beneath the plate region.

\subsection{Effect of the Subgrade Stiffness}

The effect of subgrade stiffness $k_{f}$ to the maximum vertical deflection of the plate was analyzed within interval $5-100 \mathrm{MN} / \mathrm{m}$ with the increment of $5 \mathrm{MN} / \mathrm{m}$ at the constant value of $G_{s}=38.08 \mathrm{MPa}$ and $\omega_{v}=100 \mathrm{rad} / \mathrm{s}$. The maximum vertical deflection of the plate at the midspan versus the subgrade stiffness is plotted in figure 5. The maximum vertical deflection of the plate reducing as the subgrade stiffness of the soil beneath it increasing.

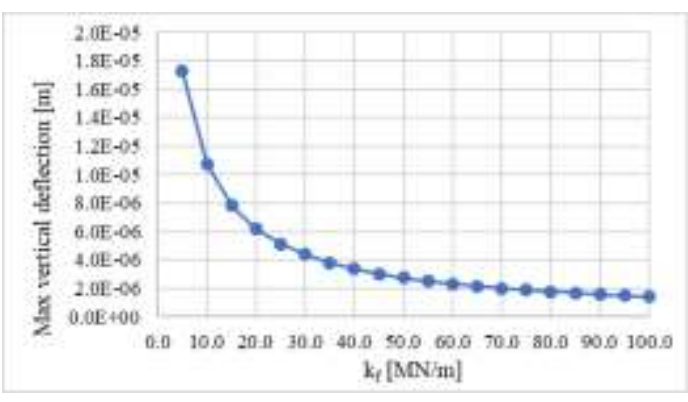

Figure 5. Maximum vertical deflection versus subgrade stiffness $\left(k_{f}\right)$.

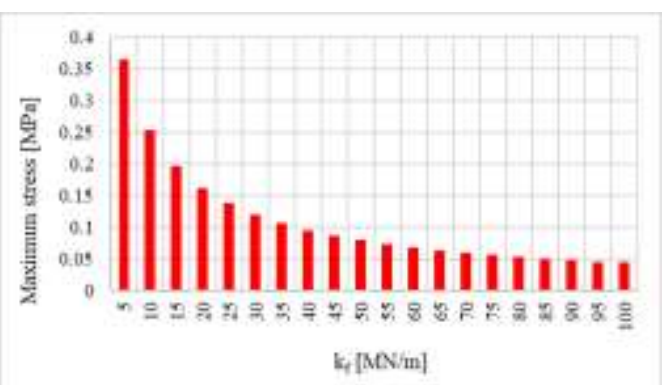

Figure 6. Maximum stress value versus subgrade stiffness $\left(k_{f}\right)$.

The maximum flexural of stress within the rigid roadway pavement region is influenced by the stiffness coefficients of the subgrade. Figure 6 depicts the maximum stress of the plate versus the subgrade stiffness of the soil beneath it for the value of $v=60 \mathrm{~km} / \mathrm{h}, \omega_{v}=100 \mathrm{rad} / \mathrm{s}$, $h=0.25 \mathrm{~m}$. Figure 6 shows that the maximum stress of the system reduces as the subgrade stiffness increases.

\subsection{Effect of the Plate Thickness}

The effect of the plate thickness $h$ to the maximum deflection and the maximum flexural stress within the plate region was analyzed in the interval $0.17-0.25 \mathrm{~m}$ with an increment of $0.02 \mathrm{~m}$. The velocity of the vehicle was $v=60 \mathrm{~km} / \mathrm{h}$ and $\omega_{v}=100 \mathrm{rad} / \mathrm{s}$. The maximum vertical deflection at mid-span versus the plate thickness is plotted in figure 7 . The maximum vertical deflection of the plate decreasing as the plate thickness increases. Figure 8 shows the maximum stress value versus the plate thickness. The plate thickness plays a very important factor in reducing the maximum flexural stress within the plate region.

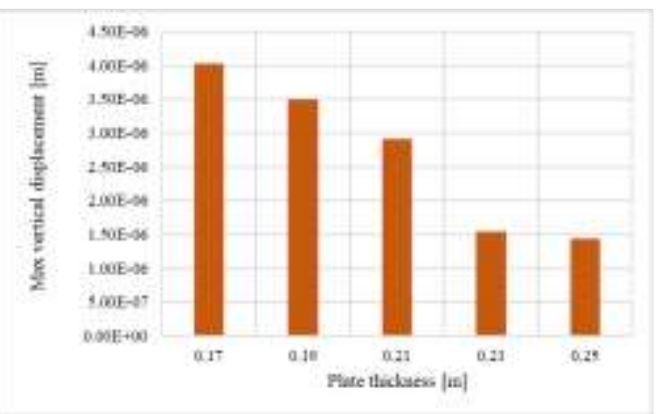

Figure 7. Maximum vertical deflection versus plate thickness.

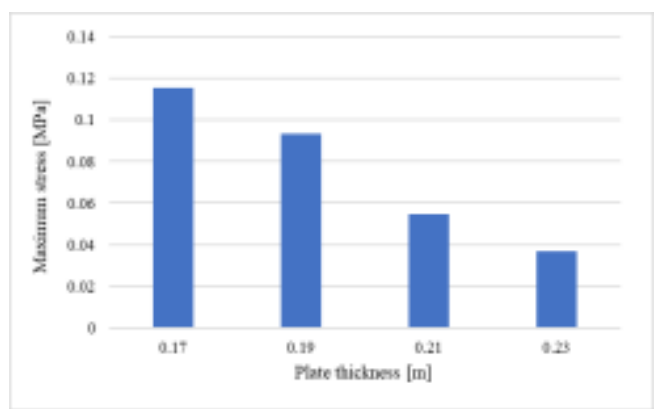

Figure 8. Maximum stress value versus plate thickness. 


\subsection{Influence of Dowel Diameter}

In this subsection, the influence of dowel diameter to the maximum flexural stress will be studied. The edge vertical translation restriction coefficients and the edge rotational restriction coefficients for the plate mentioned in this study are influenced by the size of dowel and analyzed by using the method of Friberg [11]. By using two different sizes of dowel diameter, it is possible to calculate the flexural stress distribution and the value of maximum stress with the plate region.

Figure 9 shows the flexural stress distribution within the plate region for the thickness of rigid pavement $(h)$ is equal to $0.25 \mathrm{~cm}$, the speed of the moving vehicle $(v)$ is equal to 60 $\mathrm{km} / \mathrm{h}$ and computed at $t=0.0062 \mathrm{~s}$ when the vehicle is approaching the edge of the plate. It is shown that the maximum flexural stress is influenced by dowel diameter. The maximum value of the flexural stress along the plate discontinuities can initiate cracks along the side of the pavement boundaries.

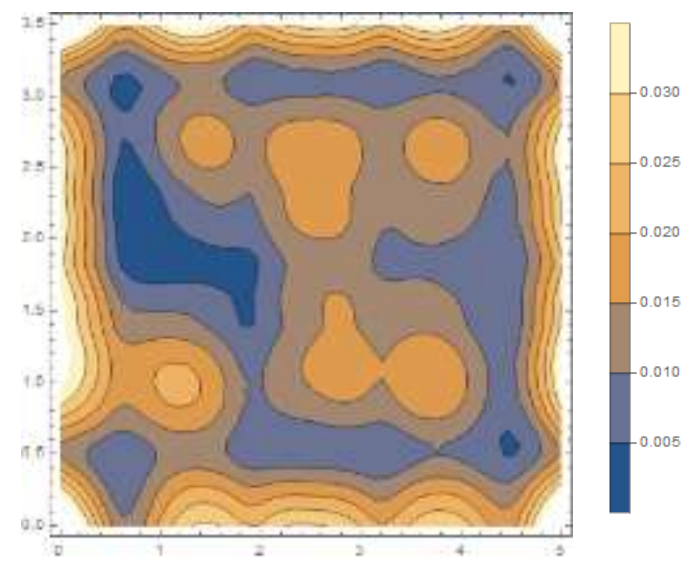

Dowel diameter $=22 \mathrm{~mm}, t=0.0062 \mathrm{~s}$

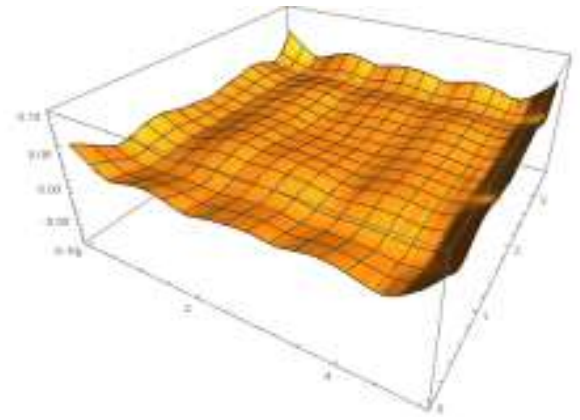

Dowel diameter $=22 \mathrm{~mm}$

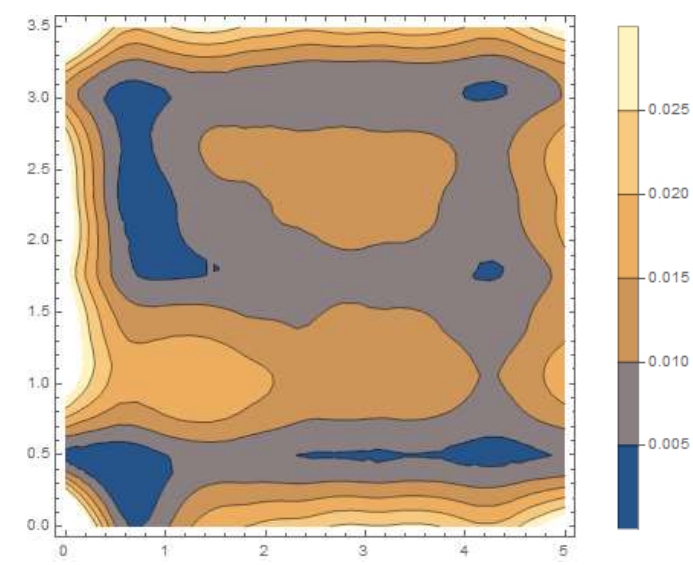

Dowel diameter $=28 \mathrm{~mm}, t=0.062 \mathrm{~s}$

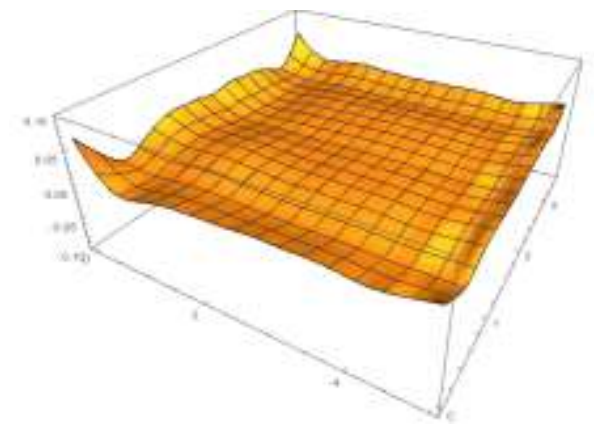

Dowel diameter $=28 \mathrm{~mm}$

Figure 9. Flexural stress distribution within the plate region.

\subsection{Results of Comparison between Modified Bolotin method and Abaqus Numerical Models}

The vertical deflection and the stress distribution in the rigid roadway pavement using the modified Bolotin are compared with the results done by Zdiri et al. in 2009 using the computer code Abaqus for static vehicle load. The data of the rigid roadway pavement are $4.00 \mathrm{~m} \times 7.00 \mathrm{~m} ; h=0.20 \mathrm{~m} ; E_{x}=E_{y}=31.10^{9} \mathrm{~N} / \mathrm{m}^{2} ; v_{x}=v_{y}=0.22$ and the weight of the vehicle is equal to 7.4.10 $\mathrm{Pa}$ [5]. Table 2 depicts the results of vertical deflections and stresses of the plate subjected to static loading at the mid-span by using different methods. 
Sofia W. Alisjahbana, Safrilah, Jouvan Chandra Putra Pratama, Ade Asmi, Irene Alisjahbana, Buntara Sthenly Gan

Table 2. Results of vertical deflections and stresses under the static loading at mid-span

\begin{tabular}{|l|c|c|}
\hline \multirow{2}{*}{ Methods } & \multicolumn{2}{c|}{ Mid-span loading } \\
\cline { 2 - 3 } & $\sigma[$ MPa] & Max vertical deflection [m] \\
\hline Westergaard [5] & 2.14 & $0.23 .10^{-3}$ \\
\hline Dantu [5] & 1.78 & - \\
\hline 3D modeling by Abaqus [5] & 1.51 & $0.40 .10^{-3}$ \\
\hline MBM method & 1.60454 & $0.2391 .10^{-3}$ \\
\hline
\end{tabular}

For the mid-span loading case, the methods of Dantu, and 3D modeling by Abaqus give very close results in stresses. The MBM method gives lower than stress than the Westergaard and Dantu methods, but higher than 3D modeling by Abaqus. However, it gives deflection only $3.8 \%$ higher than the Westergaard method.

\section{CONCLUSION}

Through the study of stress distribution in the rigid roadway pavement to the vehicle movement, the following conclusions were drawn:

a) The comparisons of the maximum vertical deflections and the maximum flexural stresses by three methods with those obtained by using the modified Bolotin method (MBM) show good correspondences although the MBM method gives results slightly higher than 3D modeling by Abaqus and lower than Westergaard and Dantu methods in stresses.

b) The MBM method is concluded a reliable method for the determination of the flexural stresses and the maximum vertical deflections in the rigid roadway pavement with discontinuities.

c) The flexural stress distribution and the maximum vertical deflection in the rigid roadway pavement are influenced by the velocity of the moving vehicle, the stiffness coefficient of the sub-grade beneath the plate, the thickness of the plate and the size of dowel diameter.

d) Compared to the past researches, this study contains several findings such as the effect of the size of dowel to the edge vertical translation restriction and the edge rotational restriction coefficients and the flexural stress distribution within the rigid pavement.

e) This work may be a great potential and a powerful tool for modeling of the rigid roadway pavement and calculating the flexural stress distribution in the pavement subjected to the moving vehicle.

\section{REFERENCES}

[1] H. Westergaard, "Analysis of Stresses in Concrete Pavements Due to Variations of Temperature," in Highway Research Board Proceedings, Washington DC, 1927.

[2] S. K. Wang, M. Sargious and Y. K. Cheung, "Advanced analysis of rigid pavements," Journal of the Transportation Engineering Division, vol. 98, no. 1, pp. 37-44, 1972.

[3] L. Fryba, Vibration of Solids and Structures under Moving Loads, Groningen: ACADEMIA, Praha, Noordhoff International Publishing, 1972.

[4] G. Lajcakova and J. Melcer, "Numerical Simulation of Moving Load on Concrete Pavements," Transport and Telecommunication, vol. 16, no. 2, pp. 145-157, 2015. 
Stress Analysis in Rigid Roadway Pavement with Discontinuities Subjected to Vehicle Movement

[5] M. Zdiri, N. Abriak and J. Neji, "Modelling of the Stresses and Strains Distribution in an RCC Pavement Using the Computer Code "Abaqus"," Electronic Journal of Structural Engineering, vol. 9, pp. 37-44, 2009.

[6] C. R. Byrum and D. Ye, "Evaluating the effect of concrete slab curling on joint load transfer responses," Journal of the Transportation Research Board, vol. 2305, no. 1, pp. 43-53, 2012.

[7] S. W. Alisjahbana, Safrilah, J. C. P. Putra, A. Asmi, S. Kiryu and B. S. Gan, "Dynamic Response of Pavement Plates to the Positive and Negative Phases of the Friedlander Load," Strength of Materials, vol. 50, no. 5, pp. 702-710, 2018.

[8] S. W. Alisjahbana, I. Alisjahbana, S. Kiryu and B. S. Gan, "Semi Analytical Solution of a Rigid Pavement under a Moving Load on a Kerr Foundation Model," Journal of Vibroengineering, vol. 20, no. 5, pp. 2165-2174, 2018.

[9] S. W. Alisjahbana and W. Wangsadinata, "Dynamic Analysis of Rigid Road Pavement under Moving Traffic Loads with Variable Velocity," Interaction and Multiscale Mechanics, vol. 5, no. 2, pp. 105-114, 2012.

[10] E. A. Lorenz, "Behavior of Dowels in Concrete Pavements," Iowa State University Capstones, 2014.

[11] D. A. Baadilla, "Dynamic Response of Orthotropic Plate on the Kerr Foundation. Master Thesis," Universitas Tarumanagara, Jakarta, Indonesia, 2001. 